\title{
NO LIMITE DO CORPO: JOÃO GILBERTO NOLL E O FIM DA MITOLOGIA
}

Fernanda Dusse*

RESUMO: A narrativa da novela $O$ quieto animal da esquina evidencia a escrita esquizofrênica e violenta de João Gilberto Noll. A partir da narração feita por seu protagonista, o leitor é levado a percorrer caminhos errantes, capazes de demonstrar a incapacidade da linguagem na elaboração de signos que deem conta da experiência. Neste percurso, a presença de instituições que representam a solidez da cultura cede lugar para a violência e o silêncio, regentes das relações humanas. A partir dessa perspectiva, este trabalho objetiva discutir como o texto de Noll revê o espaço da mitologia, da história e da cultura na sociedade contemporan buscando evidenciar, a partir de imagens do escatológico e da violencia, os desejos ainda pulsantes nos corpos ológico e da violência, os desejos ainda pulsantes nos corpos das personagens.

PALAVRAS-CHAVE: João Gilberto Noll; Mitologia; Corpo.
* fernandadusse@gmail.com

Professora no CEFET - MG, cursa Doutorado em Teoria da Literatura ela UFMG

ABSTRACT: The novel $O$ quieto animal da esquina elucidates the schizofrenic and violent writing of João Gilberto Noll. From the narration done by its protagonist, the reader is taken through wanderer routes, able to present the incapacity of language in elaborating signs to comprehend experiences. During this path, the presence of institutions which represent the solidity of culture gives place to violence and silence, dominant in the described social relationships. Within this perspective, this work aims to discuss how Noll's text reviews the space of mythology, history and culture in the contemporary society, trying to show, from images of the scatological and violence, the desires that are still vibrant in the bodies of the characters.

KEYWORDS: João Gilberto Noll; Mythology; Body 
1. SCHÜLER. Mythos e logos nos diálogos platônicos, p. 320.
O conceito de mito é de difícil definição por englobar, em seu uso corrente, perspectivas diversas e por vezes contraditórias. O conflito é latente já na aproximação dos termos gregos mythos e logos, que às vezes trata de uma relação de complementariedade, ou mesmo de pertencimento, e, em outras, de oposição. Donaldo Schüler aborda a questão já no surgimento da filosofia clássica ao demonstrar que os termos apresentam uma origem comum, já que Mito é o nome dado ao canto das musas filhas da Memória, a quem também cabe "a palavra da verdade". Assim, conclui Schüler, "Mito era a única linguagem autorizada. Os sonhos, o cálculo, o engano, o fantástico têm a mesma origem: as musas. Até a sentença dos juízes é dom das musas."

Após esse estágio inicial, em que o logos pertence ao amplo conjunto de possibilidades do mythos, inicia-se um período apresentado nos aforismos de Heráclito, em que não apenas ocorre a distinção entre as duas instâncias, como o mito é posto como a outra ordem, a ordem rejeitada. A partir desse momento, começa-se a negar a autoridade dos deuses como emissores do discurso mítico, e o logos, visto como um texto sem autor, é valorizado por tratar da busca pela verdade e a imparcialidade.

O objetivo dessa apressada digressão ao Período Clássico é demonstrar o conflito latente no trabalho com mitologias, já que ora o termo aparece para tratar de manifestações da linguagem, a partir da construção de narrativas alegóricas; ora em sentido pejorativo, como oposição à rigidez metodológica do discurso científico. Na modernidade, indica Schüler, autores como Freud, Levi-Strauss e Heidegger atualizam o debate ao retomar perspectivas antagônicas e inserir o mito em narrativas científicas que se afastam do positivismo e da percepção da civilização como progresso.

A partir disso, é possível perceber que um dos poucos aspectos que escapa à cisão no conceito de mythos e é comum aos diversos estudos de mitologia na modernidade é a relação com a tradição. Afinal, é bastante comum que a origem dos mitos esbarre na origem do mundo, pois eles comumente manifestam a existência de um estado originário, pleno e irrecuperável. Hans Blumenberg realiza um dos mais extensos trabalhos da modernidade tardia sobre o tema, e retoma princípios da psicanálise ao associar a ideia de construção do mundo à ilusão da onipotência percebida na primeira infância. Segundo o autor, a criação dos mitos, assim como "a demanda de amor da primeira infância" surge como compensação do desamparo frente a um perigo avassalador e inominável. ${ }^{2}$ Além disso, indica o autor, o mito é responsável por trazer à superfície diversos momentos da história daquela comunidade, evidenciando tradições caras para a manutenção de seus valores culturais. Dessa forma, além de trabalhar com a narrativa de um passado primordial,
2. BLUMENBERG. Trabajo sobre el mito, p. 13.
EM TESE
BELO HORIZONTE
v. 22
N. 2
MAIO-AGO. 2016
DUSSE. No limite do corpo: João Gilberto Noll e o fim da mitologia
P. $255-265$ 
o mito carrega a memória de um grupo e sua relação com o espaço e a lei.

Em outro extremo do estudo da mitologia na modernidade, Roland Barthes buscou elementos da cultura moderna francesa - como o catch ou a publicidade - para mostrar características fundamentais do pensamento mitológico al presentes. Mesmo nesse trabalho, que aparentemente está tão rigidamente inserido no momento da escrita, Barthes aponta para a relação entre mito e tradição ao concluir que "longínqua ou não, a mitologia só pode ter um fundamento histórico, visto que o mito é uma fala escolhida pela história: não poderia de modo algum surgir da natureza das coisas." Dessa forma, segundo o autor, a única maneira de se estudar um mito é percebendo sua relação com a história daquela comunidade e a memória coletiva de seus integrantes. Para Barthes, a partir desta análise, "atingimos o próprio princípio do mito: ele transforma a história em natureza." ${ }^{\prime}$

Como ficaria, contudo, a análise destas questões na pós-modernidade? Afinal, uma das marcas distintivas do período contemporâneo, responsável por separá-lo da modernidade é o que Fredric Jameson (1985) descreveu como uma esquizofrenia histórico-social:

acredito que a emergência da pós-modernidade está estreitamente relacionada à emergência desta nova fase do capitalis- mo avançado, multinacional e de consumo. Acredito também que seus traços formais expressam de muitas maneiras a lógica mais profunda do próprio sistema social. No entanto, vou limitar-me a indicar esta relação a propósito de um só de seus temas capitais: o desaparecimento do sentido de história, o modo pelo qual o sistema social contemporâneo como um todo demonstra que começou, pouco a pouco, a perder a sua capacidade de preservar o próprio passado e começou a viver em um presente perpétuo, em uma perpétua mudança que apaga aquelas tradições que as formações sociais anteriores, de uma maneira ou de outra, tiveram de preservar. ${ }^{5}$

É nítida a ruptura da contemporaneidade com as formas tradicionais do mito, já que o período não exclui o desenvolvimento científico moderno, mantendo a descrença em qualquer teoria transcendental. Entretanto, somado a isso, ocorre o esfacelamento das instituições modernas analisadas por Barthes em suas mitologias. A nação, principal organização coerciva da modernidade, se desfaz nesse capitalismo multinacional e fluido, desconstruindo também o papel social assumido pela família, a lei e mesmo o sujeito, enquanto unidade autônoma. Por isso, não é coincidência que Jameson tenha retomado as premissas estruturalistas neste seu artigo, mas enquanto Barthes o faz para mostrar que o mito é sempre uma manifestação metalinguística, Jameson, embora trate da questão histórica - e não propriamente da mitologia - aponta o fim de um saber mitológico na pós-modernidade
5. JAMESON. Pós modernidade e sociedade de consumo, p. 26.
EM TESE

v. 22

N. 2

MAIO-AGO. 2016

DUSSE. No limite do corpo: João Gilberto Noll e o fim da mitologia

p. $255-265$ 
6. JAMESON. Pós modernidade sociedade de consumo, p. 22. ao afirmar que "a experiência esquizofrênica é uma experiência da materialidade significante isolada, desconectada $e$ descontínua, que não consegue encadear-se em uma sequência coerente". ${ }^{6}$

A partir destas reflexões, o presente trabalho objetiva analisar a novela $O$ quieto animal da esquina, de João Gilberto Noll, procurando observar a relação de seu protagonista e narrador com a história e a mitologia. Em uma primeira leitura, é latente a presença dos traços esquizofrênicos apontados por Jameson e capazes de transformar a personagem de Noll em um ser errante, para quem a experiência parece impossível. Entretanto, ainda assim, existem no texto ruínas de instituições e valores culturais que, ainda que apareçam de forma desconstruída e rizomática, indicam a impossibilidade de uma ruptura completa com a tradição.

O quieto animal da esquina é o sexto livro do autor e, como todos os demais, traz como protagonista um ser anônimo errante e afastado de laços sociais. Nesta narrativa, a personagem migra de uma situação familiar mais estável (a vida com a mãe em um prédio ocupado por moradores de rua no centro de Porto Alegre) para uma relação fragmentada e confusa com os membros da casa de Kurt e Gerda, o casal germânico que o adota. Por este motivo, Manuel da Costa Pinto, na orelha da edição de 2003, da editora Francis, afirma que o livro é uma "narrativa de desconstrução", estabelecendo um jogo com o Bildungsroman, ou romance de formação. O conceito de Costa Pinto evidencia o afastamento da personagem de Noll da noção iluminista de sujeito e da frágil relação que o mesmo estabelece com a história, o meio social e as estruturas determinantes da cultura - os lugares de mitologia tratados por Barthes.

Entretanto, ao pensarmos no texto de Noll como "narrativa de desconstrução", um paradoxo se faz flagrante: como a construção da narrativa pode ser concomitante com a desconstrução de seus elementos? Ou seja, como o desenvolvimento da história pode incluir, simultaneamente, a construção linguística da narrativa e a destruição de seus elementos internos?

O caminho para responder essa pergunta precisa passar pela análise da estranha linguagem criada por Noll. Entre o lírico e o grotesco, a linguagem do autor faz transparecer o desejo de seus narradores de atordoar, fugindo das construções sintáticas convencionais e rompendo com a lógica da verossimilhança que determinaria as possibilidades linguísticas do narrador. Em O quieto animal da esquina, o protagonista pobre, que transita pelas margens da cidade, é também poeta e constroi imagens efêmeras e líricas que fortemente se afastam da narração pouco reflexiva que estrutura o texto. A linguagem não tenta, pois, organizar o caos da narrativa, mas, pelo contrário, exige que o leitor seja ali imerso, vagando sem porto, errante como suas personagens. 
7. BLUMENBERG. Trabajo sobre el mito, p. 41, tradução minha.
Nesse ponto, é possível traçar mais uma distinção entre a narrativa pós-moderna de Noll e a dos mitos. Blumenberg, em seu extenso trabalho sobre mitologia, afirma que os mitos são textos criados como tentativa de organizar o caos. Segundo o autor, "o medo é de origem arcaica, não em vista daquilo que ainda não é conhecido, mas diante do desconhecido. Enquanto desconhecido, não tem nome, não pode ser conjurado, invocado, nem abordado magicamente." Dessa forma, Blumenberg percebe o mito como tentativa de nomear o que está caótico, apossando-se, assim, de seus elementos. Para tanto, há uma combinação de estratégias narrativas (histórias são contadas na tentativa de recuperar uma origem absoluta) e descritivas (tais histórias elaboram nomes capazes de transformar o desconhecido em familiar).

A narrativa de Noll, por outro lado, trata de uma personagem anônima, sem origem ou destino. Sua trajetória rizomática não parece abrir espaço para a construção de ciclos e a escrita manifesta a falta de portos para o leitor ancorar "acumulando fatos sobre fatos e fazendo com que tudo seja arrastado pelo fluxo devastador de um tempo que corroi os seres e as coisas."

O anonimato do protagonista é, dessa forma, metáfora para o vazio da narrativa, confirmando a incapacidade da linguagem em dar conta do caos. Não se nomear equivale, metonimicamente, a não nomear nada, a romper com percepção de que a linguagem é a forma de transfigurar e esclarecer o mundo. Assim, no lugar do "sempre-igual" dos mitos, o que Noll apresenta é um estranhamento constante, a percepção única do momento presente.

O diálogo com Barthes se mostra profícuo quando percebemos que a novela, ao desconstruir verdades sociais, evidencia como elas representam mitos repetidos por vezes o suficiente para ganhar caráter de verdade absoluta. A principal destas construções míticas, como já evidenciado, diz respeito à autonomia e à consciência de unidade do sujeito. Sempre em trânsito e se reconstruindo a cada novo lugar, as personagens de Noll demonstram que não há uma consciência de unidade intrínseca à existência, evidenciando os rizomáticos processos fragilmente agrupados na construção de uma identidade. Se a capacidade de reconhecimento de si mesmo como uno é falha, também fica invalidada a crença de que há uma distinção entre eu e o outro. Fragmentados e processuais, os sujeitos se agrupam e se refratam na obra de Noll, estabelecendo colagens que incluem a si e aos outros para em seguida desfazer estes elos.

Da mesma forma, instituições fundamentais para a construção de uma consciência social coletiva são dissolvidas na novela. É o caso da nação, que aparece na trama como força de opressão, definindo, por exemplo, a relação dos empregados brasileiros com seus patrões alemães ou justificando 
9. SANTIAGO. O quieto animal da esquina, p. 74. elementos paratextuais, como o comício de Lula ou a invasão dos Sem Terra, mas incapaz de justificar a divisão entre semelhantes e diferentes ou de cercear uma zona de conforto e segurança para seus integrantes. O mesmo acontece com a instituição familiar ou com a prisão, que, desmanchadas, evidenciam as falhas sempre latentes a suas definições.

De todos os espaços - físicos ou metafóricos - responsáveis por estabelecer as fronteiras dos mitos modernos, o único que sobrevive na narrativa de Noll é o corpo. Mas um corpo que, como lembra Silviano Santiago, "não passa pelo narcisismo, pelo culto da beleza física, pela saúde e pelo aprimoramento da raça; passa pela graça e a raça do erotismo, a fome brasiliensis e pela nossa miséria larvar". ${ }^{9}$ Avaliar o que sobrevive da tradição na literatura de Noll exige assumir o corpo como única marca da vida da personagem, lugar onde a experiência aparece, mas apenas como mancha na pele. Para tanto é preciso perceber o corpo também como ruína, como espaço sempre singular e coletivo, em sua constante manifestação de desejo e violência.

O corpo, contudo, não desconstroi a ideia de esquizofrenia apresentada por Jameson como marca distintiva da pós-modernidade. Afinal, em contraposição à teoria lacaniana a personagem de Noll não confirma sua subjetividade ou inteireza ao se ver no espelho. Ao contrário, a cena, repetida em vários momentos da narrativa, apenas evidencia a distinção entre aquela figura inteira e a percepção fragmentada que ele tem de si. Mas é também frente ao espelho que a personagem percebe a passagem do tempo, rompendo com a fixação absoluta no presente, e reflete sobre seus vínculos sociais. Em uma destas cenas, ele percebe, pelo rosto barbado e com rugas, que já mora na casa de Kurt há alguns anos. Em outra, pronuncia a frase que repetirá várias vezes: "sou um homem e não estou apaixonado". Assim, mesmo sendo o corpo mais um dos elementos a confirmar a estranheza e o caos da narrativa, ele é também o responsável por articular as personagens, possibilitando ao protagonista reconhecer-se como parte de uma estrutura social e anunciando, ainda que pela desconfiguração, um senso histórico.

A primeira frase da novela também pode ser utilizada como metonímia para os corpos ali apresentados: "um caldo escuro escorrendo das minhas mãos debaixo da torneira. Eu tinha perdido o emprego, me despedia daquela graxa difícil de sair". ${ }^{10}$ Nesta cena, a personagem se confunde com o líquido, com o movimento e com a ruptura. Em uma dupla-associação, a graxa, elemento ligado à indústria, representa, simultaneamente, os preceitos modernos dos quais a contemporaneidade se despede e a realidade viscosa e suja desse homem-líquido. A sujeira representada pela graxa se derrama, ainda, sobre várias cenas que marcam a convivência entre as personagens. Afinal, as personagens de Noll quase
10. NOLL. O quieto animal da esquina, p. 7.

EM TESE

v. 22

N. 2

MAIO-AGO. 2016

DUSSE. No limite do corpo: João Gilberto Noll e o fim da mitologia

P. $255-265$ 
11. NOLL. O quieto animal da esquina, p. 19. não dialogam, mas se aproximam em cenas que apresentam o escatológico tanto na convivência diária com outros homens, quanto na agressividade do sexo com as mulheres. Como exemplo, é possível citar o relato do protagonista sobre quando foi levado para a prisão e acreditou que a convivência com os demais detentos marcaria sua rotina:

O dia clareou e eu caminhava pela cela, e cada olho que foi se abrindo eu via, em cada espreguiçar, bocejo, peido, arroto eu estava ali, vendo, e eu fazia um pouco o mesmo, também me espreguiçava, bocejava, fingia que peidava, eu arrotava e era assim que eu procurava me impregnar daqueles cinco bandidos feios e estragados. ${ }^{11}$

Entretanto, a imagem do excremento não é utilizada apenas para caracterizar a prisão, ambiente normalmente tomado como espaço da podridão humana. Pelo contrário, ela invade outros espaços e se reconfigura na forma de estupros ou de cenas de masturbação, nos diálogos tidos no banheiro do cinema ou nas lutas que marcam a relação entre Kurt e Otávio. Como exemplo, é possível apresentar a cena em que ele e Kurt voltam para casa ouvindo Bach no som do carro:

Olhei para o lado, examinei o perfil de Kurt, e sem que eu pudesse esperar, soltei um peido surdo mas que fez um cheiro bem desagradável, baixei o vidro, disse que a temperatura não estava má, o vento que corria agora na minha orelha era superfrio, Kurt talvez nem tivesse notado o fedor, ele parecia acompanhar o coral, que se divertisse com o seu coral alemão, eu de minha parte não tinha motivos de queixa, eu ia levantar o vidro que o fedor passara $[. ..] .^{12}$

Como é possível perceber por esses exemplos, o espaço da sujeira e do excremento invade o lugar da cultura e das relações sociais. Os homens retratados na novela de Noll caminham na direção contrária da evolução que marcou a modernidade, já que fazem sempre um esforço para se afastar das manifestações culturais. A ópera e o cinema aparecem aqui como manifestações exteriores, com as quais eles não são capazes de interagir. Assim, como forma de apresentar o incômodo que marca a convivência com a cultura do outro, ou, na verdade, de um outro tempo, as personagens liberam imagens de sujeira, de atitudes proibidas, de reações animalescas. Dessa forma, o escatológico se torna parte dos espaços de convivência social ao mesmo tempo em que faz emergir o absurdo que norteia tais convivências. É importante perceber que essa atitude não separa o protagonista das demais personagens, antes, pelo contrário, funciona como uma forma de aproximá-los. Os prisioneiros que pouco a pouco vão deixando que ele se contamine com suas sujeiras, os homens que, não se interessando pelo cinema, unem-se em torno do pênis do narrador, ou mesmo Kurt, que não se incomoda
12. NOLL. O quieto animal da esquina, p. 44. 
13. SANTOS. Barth, Pynchon e outras absurdetes. $O$ pós-modernismo na ficção americana, p. 8. com o fedor, rompem com a percepção do homem racional, limpo, ético. O espaço dessas personagens não é o da ordem, mas sim o do caos e do instinto, da margem, do proibido. Por esse viés, confirma-se que o processo de dessubjetivação não é característica da personagem esquizofrênica apenas, mas perpassa toda a construção social da narrativa.

Jair Ferreira dos Santos, pensando sobre a prática literária pós-modernista no Brasil, afirma que é nesse lugar frágil e marginal que a literatura estabelece morada.

$\mathrm{Na}$ sociedade atual, paradoxalmente, o mistério aumenta com o volume de informações. Falhando ao ordená-la, interpretá-la, o indivíduo é descartado pelo sistema, deslizando para o WASTE (lixo) onde se acha, no romance, a fina flor dos deserdados sociais. Improvável, a ordem supõe uma desordem crescente. Lixo, asilo, prisão, sanatório, marginália são a entropia tornada palpável. ${ }^{13}$

O protagonista de O Quieto Animal da Esquina transita por vários desses espaços: um prédio ocupado nos subúrbios de uma metrópole, a prisão, o sanatório. Entretanto, Noll propõe que o espaço do "lixo" não é mais geograficamente demarcado: durante suas andanças pela cidade ou no seio da família que o adota, o protagonista também se esconde na margem, mostrando que o espaço social habita o homem, não o contrário. Dessa forma, ao invés de dar voz ao excluído em um lugar geográfico definido - o lugar do lixo - Noll fala da exclusão na mobilidade, da presença do "lixo-humano" em todas as instituições e espaços.

Não é difícil perceber o esforço da narrativa em romper com as mitologias modernas, como denominadas por Barthes. Ao aproximar a ópera ou o cinema do escatológico, do corpo marginal, o texto ilustra o desejo de desconstruir os símbolos da modernidade e levar para o lixo todos os significantes da alta cultura. O lixo retoma assim, a ideia de caos apresentada por Blumenberg. Entretanto não há interesse, na narrativa de Noll, por ordenar ou limpar esse ambiente; pelo contrário, é na apresentação do caos que a narrativa da contemporaneidade pode ser contada. Ao mesmo tempo, tais cenas exibem uma apropriação dessas manifestações culturais, que, ao se tornarem parte do cotidiano das personagens, são marcadas também pelo escatológico. Sendo assim, o que a narrativa propõe não é propriamente a ruptura com a tradição e seus elementos simbólicos, mas a hostil tomada destes elementos, dispostos agora como mobílias da margem, adornos de um espaço essencialmente anti-mitológico.

Ainda pensando sobre os corpos violentos da novela de Noll, importa analisar as relações entre o protagonista e as mulheres, percebendo o jogo que o mesmo estabelece entre 
14. NOLL. O quieto animal da esquina, p. 10.

15. NOLL. O quieto animal da esquina, p. 15.

16. NOLL. O quieto animal da esquina, p. 12. desejo, sedução e força. A mais marcante personagem feminina da novela é a mãe do protagonista, que, segundo o mesmo, "desde que meu pai sumira, ela ali, sem mais nada a fazer que me esperar". ${ }^{14}$ Nesta fala, é notável a sobreposição da imagem do pai e a sua própria: a mãe esperava pelo marido desaparecido ou pelo filho ausente? A mesma ideia é retomada quando ele é avisado de que a mãe se mudaria para o interior do estado: "eu podia roubar a aliança do dedo da minha mãe, fugir devagarinho que ela não ia acordar, mas aquela aliança devia valer menos que uma mixaria e, principalmente, eu era um covarde". ${ }^{15} \mathrm{O}$ desejo de ter a aliança da mãe não existe pelo dinheiro que o objeto poderia lhe assegurar. Roubar e fugir devagarinho, abandonando-a, faria com que ele deixasse de ser um covarde e o aproximaria, mais uma vez, do pai, que cumpriu esse roteiro. Mais ainda o incômodo pela partida da mãe é condensado na imagem da aliança, do símbolo que marca a promessa de permanecer - promessa que parece ter sido refeita, após a partida do pai, para o filho.

Além disso, é depois dessa conversa que o protagonista encontra a vizinha Mariana e a estupra. Durante a caminhada do apartamento para o lugar onde a garota estava, ele afirma: "eu descia a escada do prédio para ver se lá embaixo tinha alguma novidade, descia a escada pensando nela, achando uma boa que fosse para São Borja”. ${ }^{16}$ Em seguida após um breve momento com a vizinha, ele a estupra, agindo como se não fosse responsável por essa ação: "agora já era tarde demais" 17 , afirma ao se dar conta que o beijo não havia sido por ela consentido. Logo após o gozo do narrador, aparece o retorno à mãe: "entrei no apartamento, a minha mãe dormia no sofá [...]”. ${ }^{18}$ A partir desses cortes estabelecidos entre o diálogo com a mãe e o encontro com Mariana, o momento do estupro e a chegada em casa, é possível pensar que há uma inter-relação entre a mãe e a menina. Mariana possibilitou a realização do desejo delineado já no apartamento, a violência que queria praticar contra a mãe que o abandonaria, assumindo novamente o papel de seu pai, do homem pelo qual ela deveria sempre esperar.

No fim da novela, outra cena de sexo assume um papel tão importante quanto esta primeira. No momento da morte de Gerda, sua mãe adotiva, eles têm uma relação sexual, construindo novamente o jogo edípico de possuir a mãe e, assim, tornar-se o pai, ao mesmo tempo em que traz mais uma vez a dualidade entre ser passivo ou ativo, responsável pela ação ou objeto da mesma. Aqui, ambas as posições estão presentes no mesmo momento. Afinal, ao mesmo tempo em que o texto traz a afirmativa de que Gerda estava muito frágil e doente para tomar decisões conscientes e que, por isso, a cena constituía um estupro, há frases no texto que colocam o protagonista como objeto dessa mulher. O narrador afirma
17. NOLL. O quieto animal da esquina, p. 12.

18. NOLL. O quieto animal da esquina, p. 12.

EM TESE

BELO HORIZONTE

v. 22

N. 2

MAIO-AGO. 2016

DUSSE. No limite do corpo: João Gilberto Noll e o fim da mitologia

P. 255-265 
19. NOLL. O quieto animal da esquina, p. 58.

20. SANTIAGO. $O$ evangelho segundo São João, p. 77. que era Gerda quem o segurava e o puxava para perto de si, oferecendo um convite para o sexo, apresentando-se disponível. Ele apenas se deixava ser puxado, "arrancado" de si pelas mãos da mulher. A sintonia dos dois, guiada por Gerda, só é rompida quando ele percebe que "seu corpo arrefeceu, murchou, paralisou" ${ }^{19}$, ao contrário do dele, ainda pulsando

A relação entre as cenas citadas e a mitologia é latente. Afinal, para falar do desejo de ter relações sexuais com a mãe, Freud recorreu ao mito grego de Édipo, usando-o como metáfora para a pulsão incestuosa e a proibição desta pela cultura. Em Totem e tabu, o psicanalista retomou esta ideia, indicando que a interdição do incesto não acontece apenas no ocidente, mas é lei fundamental de quase todas as culturas. A análise que Freud fez dos mitos permite, pois, que os aproximemos da ideia de moral e da castração das pulsões. Nesta leitura, valores e limites da convivência socia são expressos pela narrativa mítica, que, ainda que de forma alegórica, manifesta as leis não-escritas daquele grupo. Isso significa que cabe apenas ao corpo do outro - da personagem invocada pelo texto mítico - o prazer da pulsão proibida e a dor por seu castigo.

Noll certamente estabelece um diálogo promissor com a tradição por possibilitar a ruptura com a cultura e a concretização deste desejo reprimido, mas, diferente de tantos autores que utilizam do espaço da ficção para questionar o tabu do incesto, o autor constrói uma narrativa em que a culpa pelos atos cometidos cede espaço para a cisão de opostos. Dessa forma, dominar e ser dominado, ser pai e ser filho, ocupar e ser tomado aparecem como imagens complementares e ambivalentes.

Ao longo de todo o texto, é o corpo o elemento responsável por subverter a moral estabelecida e transformar os paradigmas da mitologia moderna em partes do cotidiano marginal e impuro das personagens. Os buracos do corpo dão vazão aos desejos culturalmente reprimidos e se permitem ser penetrados por todas as sujeiras da sociedade. O corpo não aceita a invocação do texto mítico, não racionaliza, não nomeia. $\mathrm{O}$ corpo se permite desejar e, tomando como blasfêmia a religião, transforma cotidianamente o verbo em carne, em gozo. Ao leitor de Noll, resta navegar por um mar sempre aberto, sem porto na tradição, por esta escrita que parece surrealista e compõe um "borbulhar anárquico", como definiu Silviano Santiago. À deriva, o leitor se depara com um texto de fruição, de gozo, em que o "erotismo repousa no poro do corpo: merda e palavra" ${ }^{20}$. Textos que apontam para a irracionalidade, a incerteza. Textos carnais, suportes para corpos imundos, escancarados, decompostos.

Assim, a ruptura final com o mito é feita por este corpo lacunar, incapaz de reconhecer o que não pode ser tocado. A sinestesia, a percepção sensível do mundo, de seus cheiros 
azedos, seus gostos apodrecidos, afasta a personagem de Noll da crença mítica na unidade, na origem ou na transcendência. Em comum com o mito, resta apenas a sensação eterna do presente, a percepção esquizofrênica, mais nítida e mais intensa, de sempre um único instante.

\section{REFERÊNCIAS}

BARTHES, Roland. Mitologias. Tradução de Rita Buongermino e Pedro de Souza. Rio de Janeiro: DIFEL, 1978.

BLUMENBERG, Hans. Trabajo sobre el mito. Tradução de Pedro Madrigal. Barcelona: Paidós, 2003

COSTA PINTO, Manuel da. Orelha. In: NOLL, João Gilberto. 0 quieto animal da esquina. Brasília: Francis, 2003.

FREUD, Sigmund. Totem e tabu: algumas concordâncias entre a vida psíquica dos primitivos e dos neuróticos. Tradução de Paulo César de Souza. São Paulo: Penguin \& Companhia das Letras, 2013.

JAMESON, Fredric. Pós modernidade e sociedade de consumo. Tradução de Vinicius Dantas. Novos Estudos CEBRAP, São Paulo, n. 12, 1985.

NOLL, João Gilberto. 0 quieto animal da esquina. Brasília: Francis, 2003.

SANTIAGO, Silviano. O evangelho segundo São João. In: Nas malhas da letra: ensaios. Rio de Janeiro: Rocco, 2002.
SANTOS, Jair Ferreira dos. Barth, Pynchon e outras absurdetes. pós-modernismo na ficção americana. In: Pós-modernidade. São Paulo: Editora Roberto Cardoso de Oliveira, 1988.

SCHÜLER, Donaldo. Mythos e logos nos diálogos platônicos Letras Clássicas, São Paulo, n. 2, 1998. 